\title{
Upper limb defect associated with developmental delay, unilateral poorly developed antihelix, hearing deficit, and bilateral choroid coloboma: a new syndrome
}

\author{
John R Ward, Criseida Saad de Owens, Iván A Sierra
}

\begin{abstract}
Two sibs are reported with upper limb defect, developmental delay, central hearing loss, unilateral poorly developed antihelix, and bilateral choroid coloboma. The inheritance is probably autosomal recessive.
\end{abstract}

A number of syndromes are characterised by radial ray defects, deafness, ear abnormalities, and heart defects, which may be autosomal, sex linked, multifactorial, chromosomal, or teratogenic. We present two sibs with upper limb malformations, retarded skeletal maturation, poorly developed antihelices, developmental delay, central hearing deficit, and bilateral choroid coloboma. The identification of this association will assist in genetic counselling.

\section{Case reports}

\section{CASE 1}

This 6 year old female was born at 36 weeks' gestation to a 21 year old mother and an unrelated 30 year old father. Birth weight was $2700 \mathrm{~g}$. She is the fourth of five children from

\section{Clinical Genetics Section and Neonatology Service, Complejo Hospitalario Metropolitano de la Caja del Seguro Social Arnulfo Arias M, Panama City, Panama. \\ J W Ward \\ C Saad de Owens \\ I A Sierra}

Correspondence to

Dr Ward, PO Box 10378, Zona 4, Panama, Republic of Panama.

Received 9 October 1990. Revised version accepted 2 January 1992.
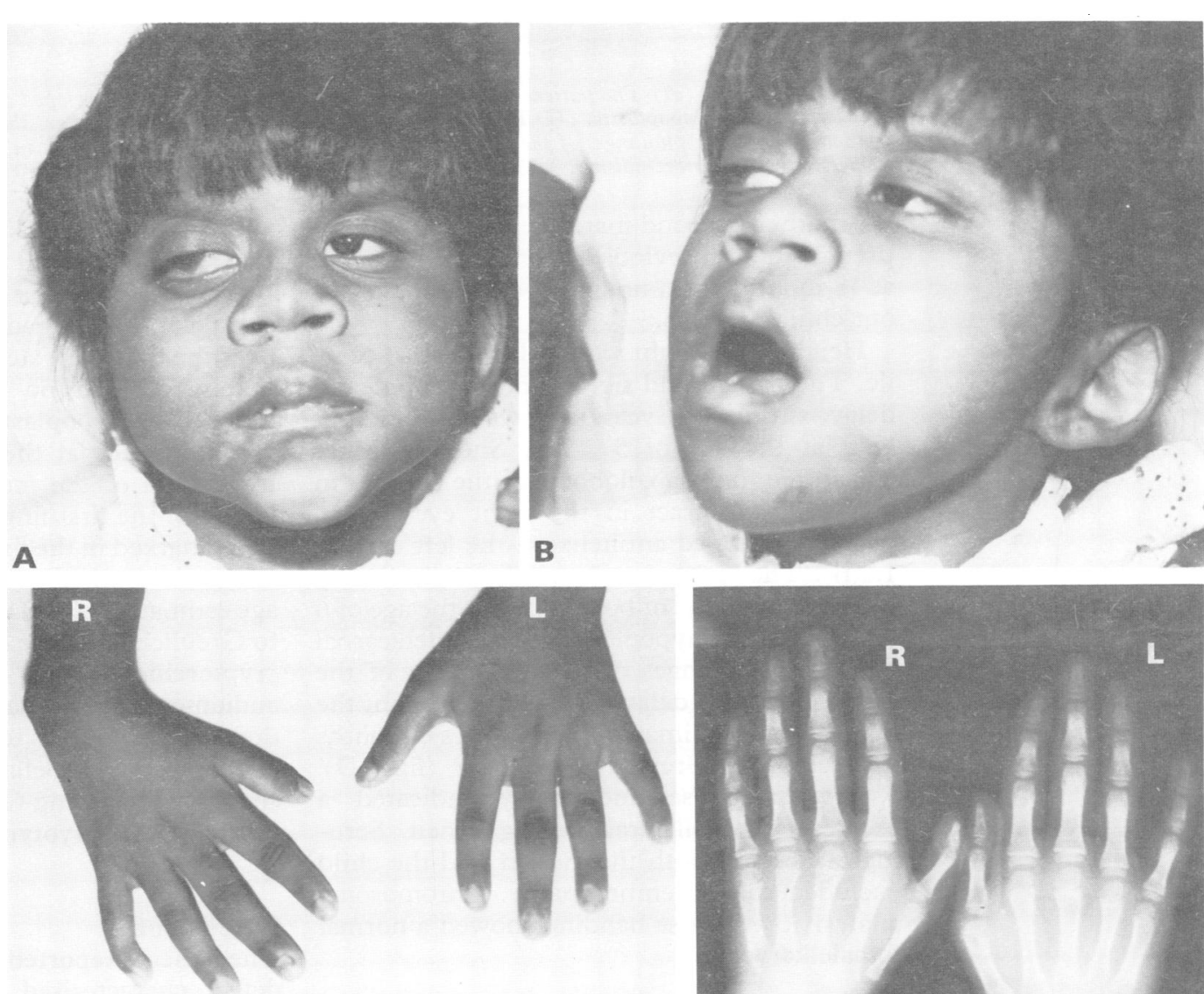

C

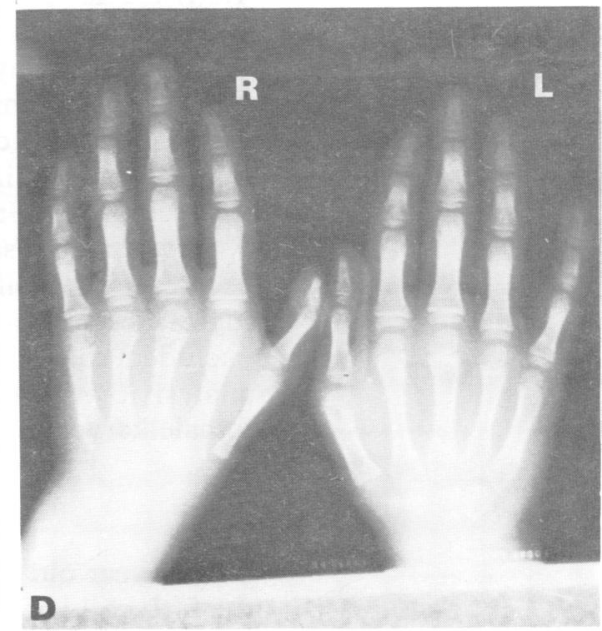

Figure 1 Case 1. (A) and (B) The patient at the age of 6 years showed inner epicanthic folds, coloboma of the choroid in both eyes, cataract in the right eye, and poorly developed antihelix on the left ear. (C) The right thumb is hypoplastic. (D) Radiographs of both hands at the age of 6 years indicated hypoplasia of the metacarpal and the phalanges of the first finger of the right hand. 

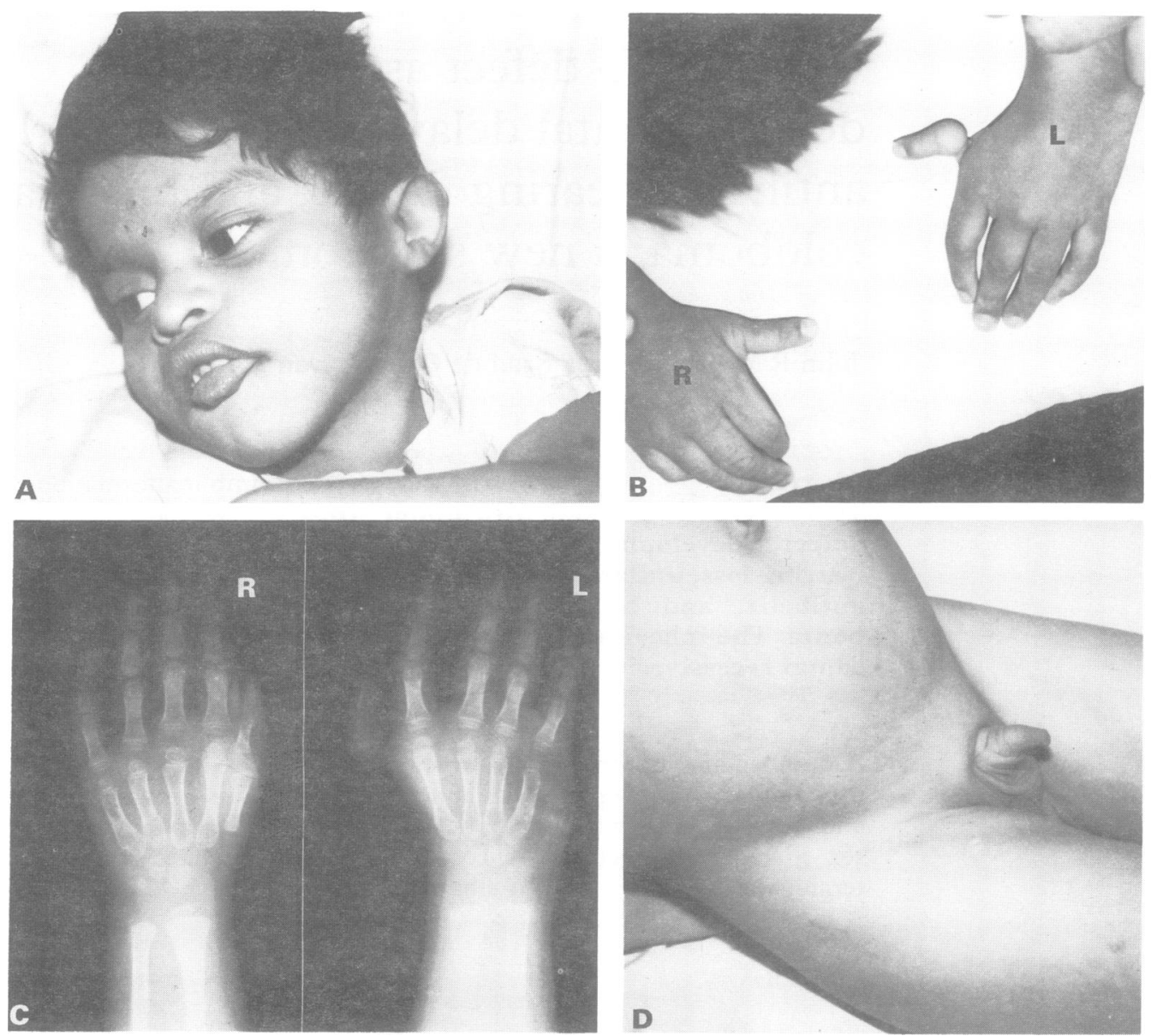

Figure 2 Case 2. (A) The patient at the age of 5 years showing a poorly developed antihelix on the left ear. (B) The left thumb is hypoplastic. (C) Radiographs of both hands at the age of 5 years showed hypoplasia of the metacarpal and the phalanges of the first finger of the right hand, more pronounced in the first finger of the left hand. (D) Bilateral cryptorchidism.

the mother's second marriage; of the two children from her previous liaison, the oldest died at 18 months from unknown causes and without clinical details.

Height and weight were below the 3 rd centile. The patient had significant developmental delay, sitting at 4 years and walking without help at the age of 5 years. She had inner epicanthic folds, a coloboma of the choroid in both eyes, cataract in the right eye, and a poorly developed antihelix on the left ear (fig 1A,B). The right thumb was hypoplastic (fig 1C). Radiographs of both hands at the age of 6 years showed hypoplasia of the metacarpal bone and phalanges of the first finger of the right hand with delayed bone maturation; the bone age was estimated to be 3 years 6 months according to Greulich and Pyle (fig 1D). Evoked response audiometry indicated a severe central bilateral hearing deficit. Serological tests in both the mother and the child excluded rubella embryopathy. Chromosome analysis by Giemsa banding showed a normal female karyotype.

\section{CASE 2}

This 5 year old male, a brother of case 1 , and the fifth child of the second marriage, was born with a birth weight of $2300 \mathrm{~g}$, his Apgar scores being 6 and 9 . Height and weight were below the 3 rd centile. He showed significant developmental delay, being unable to crawl or walk and with no speech. There was a coloboma of the choroid in both eyes. The anithelix was poorly developed in the left ear (fig 2A). A systolic murmur grade $3 / 6$ could be heard best over the lower left sternal border. Echocardiography showed no abnormalities. The left thumb was hypoplastic (fig 2B). Radiographs of both hands at the age of 5 years showed hypoplasia of the metacarpal bone and phalanges of the first finger of the right hand and more marked in the first finger of the left hand. Bone maturation was delayed with the bone age estimated to be 3 years 6 months according to Greulich and Pyle (fig 2C). He had bilateral cryptorchidism (fig 2D). Evoked response audiometry showed a severe bilateral hearing deficit. Serological tests on the mother and child excluded rubella embryopathy. Chromosome analysis using Giemsa banding showed a normal male karyotype.

\section{Discussion}

The patients reported here have an upper limb defect characterised by hypoplastic thumb, unilateral poorly developed antihelix, and bilateral coloboma of the choroid. Evoked response audiometry showed severe bilateral hearing deficit. Height and weight are below the 3 rd centile and there is significant developmental delay.

The differential diagnosis is from existing syndromes characterised by radial ray defects, 
deafness, and ear abnormalities. Features of the Holt-Oram syndrome are upper limb defects which vary from hypoplasia of the thumb to phocomelia and cardiac anomaly, ${ }^{1}$ but there are no ear or eye defects, hearing deficit, or developmental delay. The lacrimo-auriculardento-digital syndrome is characterised by obstruction of the nasolacrimal duct, aplasia or hypoplasia of the lacrimal puncta, cup shaped ears, hearing loss, hypodontia, and variable abnormalities of the upper limbs. ${ }^{2}$ Neither of the sibs described here had any disturbance of lachrymation or dentition.

Rudimentary or absent thumb, ear defect, and hearing deficit are features of facioauriculoradial dysplasia, ${ }^{3}$ which includes features not present in either of the sibs described here, such as dysmorphic facies characterised by midfacial depression and deformities of the pinnae which are primitively formed. The features of Nager syndrome are hypoplasia or aplasia of the thumb, deformed ears, and hearing deficit. ${ }^{4}$ The facial appearance is characterised by malar hypoplasia with downward slanting palpebral fissures and partial to total absence of the lower eyelashes; these features are not present in the sibs described here.

Thumb defects, auricular anomalies, and occasional deafness are features of Townes syndrome. ${ }^{4}$ This syndrome can be differentiated from that of our patients by hemifacial microsomia, preauricular tags, and anal defects including imperforate anus. Malformations of the extremities (thumb deformity) and short stature are features of Fanconi syndrome. ${ }^{4}$ The brownish pigmentation, the presence of chromosomal breakage, and the progressive marrow hypoplasia differentiate this syndrome. ${ }^{4}$

The phenotype of the patients described in this paper suggests a new syndrome and the occurrence in sibs born to normal parents makes autosomal recessive inheritance likely.

1 Holt M, Oram S. Familial heart disease with skeletal malformation. Br Heart $\mathcal{F}$ 1960;22:236-42.

2 Hollister DW, Klein SH, De Jager HJ, Lachman RS Rimoin DL. The lacrimo-auriculo-dento-digital syndrome. F Pediatr 1973;83:438-44.

3 Harding AE, Hall CM, Baraitser $\mathrm{M}$. Autosomal dominant asymmetrical dysplasia, dysmorphic facies, and conductive hearing loss (facioauriculoradial dysplasia). $\mathcal{f}$ Med Genet hearing loss (facic

4 Jones KL. Smith's recognizable patterns of human malformation. 4th ed. Philadelphia: Saunders, 1988:216-9, 274-5. 